\title{
Study of Incidence of Carcinoma Prostate in Central India With Reference To Gleason's grading
}

\author{
Jain VK' Khare $V^{2}$, Tantuway $R^{3}$ \\ ${ }^{1}$ Dr Vivek Kumar Jain, Assistant Professor, Department of Pathology, ${ }^{2}$ Dr Vivek Khare, Assistant Professor, Department of \\ Pathology, ${ }^{3}$ Dr Rajendra Tantuway, Tutor, Department of Pathology, All from L N Medical College, Bhopal, India
}

Address for correspondence: Dr Vivek Kumar Jain, Email: dr.vivekjain@yahoo.co.in

\begin{abstract}
Introduction: Prostate cancer is the most common non dermatologic cancer and the second most common cause of cancer related death in men. Although most prostate cancers are relatively slow growing and remain clinically unrecognized, their course is often unpredictable in terms of its speed of progression, perhaps because of the considerable heterogeneity of the histologic grade and a multitude of other factors that affect tumor growth. Material and method: The present study was carried out in the Department of Pathology, L.N. Medical College, Bhopal, India. It was both a prospective and a retrospective study of 310 prostatic biopsies /TUR (Trans-urethral resection) prostate chips. Result: Among 310 Prostate biopsies, 276 cases (89\%) were of benign prostatic hyperplasia, 8 cases $(2.5 \%)$ were of benign prostatic hyperplasia with prostatic intraepithelial neoplasia and 26 cases $(8.38 \%)$ were of adenocarcinoma prostate. Discussion: Higher incidence of adenocarcinoma prostate could be due to the fact that in the absence of proper screening programme in our country, majority of the tumours are diagnosed incidentally when patients present with obstructive symptoms.
\end{abstract}

Key words: Adenocarcinoma prostate, PSA, Gleasons grading,

\section{Introduction}

Adenocarcinoma is most common malignancy of the prostate gland and one of the leading causes of cancer related death in males. The American Cancer society estimated that, in the USA, 2, 34,460 males would be diagnosed with prostate cancer in 2006 \& 27,350 would die of their disease ${ }^{1}$. Prostate cancer is the most common cancer in men ,accounting for $33 \%$ of all malignant tumors in men \& accounts for $9 \%$ of cancer deaths, the third highest in men after lung \& colorectal cancers ${ }^{2,3}$

Manuscript received: $11^{\text {th }}$ Aug 2013

Reviewed: $26^{\text {th }}$ Aug 2013

Author Corrected: $29^{\text {th }}$ Aug 2013

Accepted for Publication: $23^{\text {rd }}$ Sep 2013
.Hormonal factor appear to play a role in the development of prostate carcinoma. The disease does not occur in eunuchs castrated before puberty and its incidence is low in patients with hyperestrogenism. It has been estimated that $5 \%$ to $10 \%$ of prostate carcinoma have a genetic link. There is no demonstrable correlation with diet, Sexually transmitted diseases, sexual habit, smoking or occupational exposure ${ }^{4}$.

Almost $75 \%$ of men diagnosed with prostatic cancer are 65 or older, but the tumors can be seen in younger adults and even in children and adolescents. ${ }^{5}$ Their frequency increases with age, a fact well substantiated by careful 
observation at autopsy. The frequency with which incidental carcinoma is found at post-mortem examination varies between $15 \%$ to $70 \%$ and is directly related to the age of patient and the thoroughness of the sampling. ${ }^{4}$ The combination of digital rectal examination, trans rectal ultrasonography and serum PSA represent a powerful diagnostic triad for the detection of early prostate carcinoma ${ }^{6}$.

\section{Material and Methods}

The present study was carried out in the Department of Pathology, L.N. Medical College, Bhopal. It was both a prospective and a retrospective study of 310 patients whose prostatic biopsies /TUR (Trans-urethral resection) prostate

\section{Results}

Table No. 1: Number of Cases of Prostate Gland biopsies

\begin{tabular}{|c|c|c|}
\hline Diagnosis of Cases & Number of cases & Percentage \\
\hline Benign prostatic hyperplasia & 276 & $89 \%$ \\
\hline BPH with PIN & 8 & $2.50 \%$ \\
\hline Adenocarcinoma prostate & 26 & $8.3 \%$ \\
\hline
\end{tabular}

As per table, 310 cases of prostatic biopsies were studied; these cases usually were labelled as benign prostatic hyperplasia but microscopic studies showed that only $89 \%$ were of pure benign prostatic hyperplasia (BPH), $2.5 \%$ were of BPH with prostatic intra-epithelial neoplasia \& $8.38 \%$ were of adenocarcinoma prostate.

\section{Table No. 2: Distribution of Cases as Per Procedure}

\begin{tabular}{|c|c|c|}
\hline Procedure & Number of cases & Percentage \\
\hline Biopsy & 12 & $3.87 \%$ \\
\hline Prostatectomy & 44 & $14.19 \%$ \\
\hline TURP & 254 & $81.93 \%$ \\
\hline Total & 310 & $100 \%$ \\
\hline
\end{tabular}

Maximum number of cases were between age group of 60 to 70 year [table no 3], data indicates that majority of cases of carcinoma prostate in our setup are diagnosed through histopathological examination of TUR prostate chips [table 2]. 
Table No. 3: Age distribution of cases of Prostate Gland Tumours Including BPH with Adenocarcinoma Prostate

\begin{tabular}{|c|c|c|}
\hline Age Group & Number of cases & Percentage \\
\hline $\mathbf{4 0 - 4 9}$ years & 12 & $3.87 \%$ \\
\hline $\mathbf{5 0 - 5 9}$ years & 44 & $14.19 \%$ \\
\hline $\mathbf{6 0 - 6 9}$ years & 137 & $44.19 \%$ \\
\hline $\mathbf{7 0 - 7 9}$ years & 98 & $31.60 \%$ \\
\hline $\mathbf{8 0}+$ years & 19 & $6.12 \%$ \\
\hline Total & 310 & $100 \%$ \\
\hline
\end{tabular}

Table No. 4: Gleason Score as per Specific Grouping of Cases of Carcinoma Prostate

\begin{tabular}{|c|c|c|}
\hline Gleason Score & Number of cases & Percentage \\
\hline $\mathbf{2 - 4}$ & 7 & $26.92 \%$ \\
\hline $\mathbf{5 - 6}$ & 6 & $23.00 \%$ \\
\hline $\mathbf{7}$ & 5 & $19.23 \%$ \\
\hline $\mathbf{8 - 1 0}$ & 8 & $30.76 \%$ \\
\hline Total & 26 & $100.00 \%$ \\
\hline
\end{tabular}

According to Gleason score ${ }^{10}$ maximum no. of cases were of score 8 to 10 [table 4], and primary Gleason grade is mainly grade $3,4 \& 5$ were present in $8,6, \& 6$ pateints respectively.

Table No. 5: Mean PSA with Gleason Score

\begin{tabular}{|c|c|c|}
\hline Gleason Score & Mean PSA (ng/ml) & Standard Deviation \\
\hline $\mathbf{2 - 4}$ & 12 & 4.5 \\
\hline $\mathbf{5 - 6}$ & 15 & 7.8 \\
\hline $\mathbf{7}$ & 23.5 & 14.1 \\
\hline $\mathbf{8 - 1 0}$ & 26.6 & 16.0 \\
\hline
\end{tabular}


Table No. 6: Relationship of Mean Gleason Score and Age

\begin{tabular}{|c|c|c|}
\hline Age & Mean Gleason Score & Standard Deviation \\
\hline $\mathbf{5 0 - 5 9}$ & 5 & 2.1 \\
\hline $\mathbf{6 0 - 6 9}$ & 7.4 & 1.7 \\
\hline $\mathbf{7 0 - 7 9}$ & 7.0 & 2.2 \\
\hline $\mathbf{8 0 - 8 9}$ & 8.0 & 2.0 \\
\hline
\end{tabular}

Data suggest that with increasing Gleason's score ${ }^{10}$, serum PSA levels increase and probability of metastatic disease may increase as well [table 5]. Data indicate that amongst carcinoma prostate, cases presenting in a higher age group had Gleason score more than that patients presenting in a younger age group [table 6].

Table No. 7: Age distribution of carcinoma prostate

\begin{tabular}{|c|c|c|}
\hline Age & Number of cases & Percentage \\
\hline $\mathbf{5 0 - 5 9}$ years & 4 & $15.38 \%$ \\
\hline $\mathbf{6 0 - 6 9}$ years & 9 & $34.61 \%$ \\
\hline $\mathbf{7 0 - 7 9}$ years & 11 & $42.30 \%$ \\
\hline $\mathbf{8 0 - 8 9}$ years & 2 & $7.69 \%$ \\
\hline Total & 26 & $100 \%$ \\
\hline
\end{tabular}

Table 8 indicate that maximum number of cases of carcinoma prostate present in between age group of 70 to 79 years.

\section{Discussion}

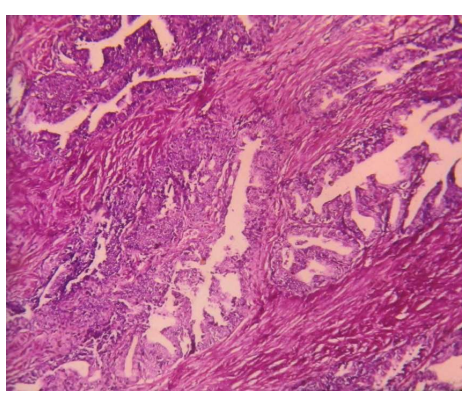

Fig 1: Adenocarcinoma of prostate gleason grade 1+1

Carcinoma may arise in any zone of the prostate, but the relative distribution is different in each zone, $68 \%$ of the

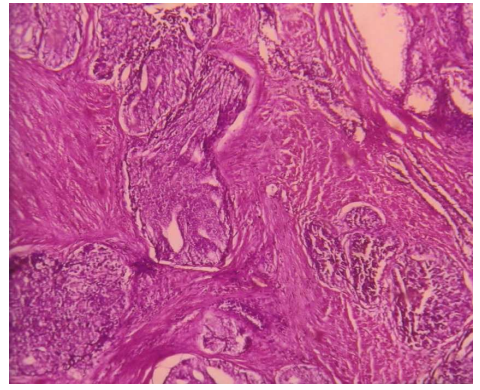

Fig 2: Adenocarcinoma of prostate gleason grade $5+5$ carcinoma arises in the peripheral zone, $24 \%$ in the transition zone and $8 \%$ in the central zone ${ }^{7}$. Various patterns

Available online at: $\underline{\text { ww.ijmrr.in }} \quad 172$ | P a g e


of growth have been well described by Mostofi \& Price ${ }^{8}$, and Gleason ${ }^{9}$, they include acinar, fused acinar, cribriform, papillary, trabecular and solid. Although numerous grading systems for carcinoma have been proposed, only the Gleason grading system has prevailed. Gleason designed this system to accommodate the fact that carcinoma of the prostate has different pattern of growth and each may range from well differentiated to poorly differentiated, with usually more than one pattern in any prostatic carcinoma. In the Gleason system the two predominant patterns [primary and secondary] are recorded.

The sum of these pattern constitute a score which ranges from 2 to $10 .{ }^{10}$ The probability of developing prostate cancer increases from $0.005 \%$ in men younger than 39 years to $2.2 \%$ in men between 40 and 59 years and $13.7 \%$ in men between 60 and 79 years $^{11,12}$. The current lifetime risk of developing prostate cancer is $16.7 \%$ ( 1 in 6 men). The probability of developing histological evidence of prostate cancer is even higher. Carter and colleagues ${ }^{13}$ showed that $50 \%$ of men between 70 and 80 years of age have some histological evidence of malignancy. A lifetime risk of $42 \%$ for developing histological evidence of prostate cancer in 50 -year-old men has been calculated ${ }^{13}$, 14. In men at this age, however, the risk of developing clinically significant disease is only $9.5 \%$, and the risk of dying from prostate cancer is only $2.9 \%{ }^{9}$.

Incidence of Prostate cancer escalates dramatically with increasing age. Although it is a very unusual disease in men younger than 50 years, rates increase exponentially thereafter. The registration rate by age cohort in England and Wales increased from eight per thousand population in men aged 50 to 56 years to 68 per thousand in men aged 60 to 64 years, 260 per thousand in men aged 70 to 74 years, and peaked at 406 per thousand in men aged 75 to 79 years ${ }^{15}$. In this same population, the death rate per thousand in 1992 in cohorts of men aged 50 to 54 years, 60 to 64 years, and 70 to 74 years was 4,37 , and 166 respectively ${ }^{15}$.

Dalkin BL et al in their studies found that after 50 years of age, both incidence and mortality rates from prostate cancer increases. By age 80 years, approximately $60 \%$ to
$70 \%$ of men have evidence of carcinoma at autopsy ${ }^{16}$. Aprikian AG in their studies of 151 cases of carcinoma prostate in men younger than 50 years found that $4.6 \%$ of cases were $<40$ years, $15.3 \%$ were in the age group $40-44$ years, $80.1 \%$ were $45-49$ years. ${ }^{17}$ In our study we found increased prevalence with age advanced age.

The tissue specificity of PSA makes it the most useful tumour marker available for screening and management of carcinoma. Lack of cancer specificity is the only drawback as it can be raised in benign condition as well. Normal value in men ranges from $0-4 \mathrm{ng} / \mathrm{ml}$. Reissiggi et al studied 21,078 volunteers of which 1618 had elevated PSA levels. Of these men, 778 (48\%) underwent biopsies, 197 biopsies $(25 \%)$ were positive for prostate carcinoma and 135 patients underwent radical prostatectomy. ${ }^{18}$ A case-control study from a population-based cohort in Sweden estimated that a PSA level $\leq 1 \mathrm{ng} / \mathrm{mL}$ at age 60 was associated with an extremely low risk of prostate cancer metastasis $(0.5$ percent) or death from prostate cancer $(0.2$ percent $)$ by age $85^{19}$.

Simulation models using data from Surveillance Epidemiology and End Results (SEER) registries suggest that PSA screening could account for 45 to 70 percent of the observed decline in prostate cancer mortality rates, mainly by decreasing the incidence of distant stage disease 20. The European Randomized Study of Screening for Prostate Cancer (ERSPC) investigators used simulation models based on their data and observational studies reporting quality of life outcomes to project lifetime numbers of cancer diagnoses, treatments, deaths, and quality-adjusted life years gained after PSA screening ${ }^{21}$. Overall, annual screening between ages 55 to 69 would result in nine fewer prostate cancer deaths per 1000 men followed for an entire lifetime.

A study by Carter and associates ${ }^{22}$ demonstrated that 65 year-old men with low PSA serum levels are at low risk for developing prostate cancer, and it is unlikely that they will be diagnosed with prostate cancer during the next decade. This study suggests that less intensive PSA screening could maintain the detection of the majority of prostate cancers 
in men up to the age of 75 years and markedly reduce unnecessary PSA testing for men with low PSA serum level. The data suggests that with increasing Gleason's score, serum PSA levels increase and thus probability of metastatic disease may increase. In our study we did not find any case of carcinoma prostate with serum PSA level less than $10 \mathrm{ng} / \mathrm{ml}$.

Majority of procedure done were of TURP and we in our study adopted the strategy of complete processing of TUR chips.

Of all the tumours of prostate gland, prostate carcinoma has the greatest clinical significance. $96 \%$ of the prostatic cancers are adenocarcinomas, other histological types are transitional cell carcinoma $2 \%$, squamous cell carcinoma and undifferentiated carcinoma 2\%. In our study all 26 cases $(100 \%)$ were of prostate adenocarcinoma.

We graded the specimen across the full spectrum of Gleason score, ${ }^{10}$ GS 2-10 and also classified specific grouping of grades, that separated the cases into more clinically meaningful categories. These categories included GS 2-4, GS 5-6, GS 7 and GS 8-10

Lilieby W conducted a study to evaluate and compare the impact of two major histological grading system on failure free survival in patients with prostate carcinoma specimen from 178 patients obtained were reviewed simultaneously by two pathologies assigning WHO and Gleason grade. They concluded that the Gleason grouping resulted in better prognostic separation of patients. Out of a total of 178 patients, 44 were GS $<7,58$ were GS-7. 78 were GS $8-10 . .^{23}$

In our study13 cases were GS $<7,5$ cases were GS 7, 8 cases were GS 8-10.

Albertsen and coworkers ${ }^{24}$ clearly demonstrated that men with low-grade prostate cancer are at low risk for disease progression even after 20 years of watchful waiting or androgen deprivation therapy. Men with Gleason 7 and 8 to 10 were found to be at high risk of dying from prostate cancer. After 20 years, only 3 of 217 patients survived. Men with moderate-grade disease have intermediate cumulative risk of prostate cancer progression after 20 years of followup. On analysis of mean Gleason's score with age we found that with increasing age, the mean Gleason score was also increased.

Our study reported 8 cases of benign prostatic hyperplasia with prostatic intraepithelial neoplasia. These are the precursor of malignancy. PIN divided into low grade (I / II) and high grade (III). These are the predictor of future malignancy and malignancy more in higher grade PIN.

\section{Conclusion}

In our study among all the cases of prostatic carcinoma all cases were of Adenocarcinoma prostate (100\%). Adenocarcinoma prostate were graded as per Gleason's microscopic grading system, showing $26.92 \%$ with GS 24, and $30.26 \%$ with GS 8-10. Majority of the tumours had a high Gleason score.

This could be due to the fact that in the absence of proper screening programme in our country, majority of the tumours are diagnosed incidentally when patients present with obstructive symptoms, by which time the tumours have already spread beyond the confines of prostate.

Mean serum PSA was found to increase with Gleason score. Majority of prostatic carcinoma are incidentally diagnosed on routine TUR of prostate. Needle biopsy of prostate is not highly practiced by the surgeons. Grading is a valuable research tool. It can separate cases into subsets of comparable malignancy to facilitate analysis of treatment results and other factors that might vary between tumours of differing malignancy.

Similarly grading can be used to stratify patients for balanced randomization into comparable treatment groups in clinical trials. In the management and treatment of prostate cancer, the clinician must first evaluate the clinical stage of the tumour and then the age and general health of the patient.

The histological grade should be part of the clinical staging, using the level of malignancy of tumour to choose the treatment offering the greatest benefit to risk ratio. Chin 
Chen $\operatorname{Pan}^{25}$ studied the prognostic significance of tertiary Gleason patterns of higher grade in radical prostatectomy specimen. He stated that the Gleason grading system did not account for the existence of a tertiary (third more prevalent) pattern.

Funding: Nil

Conflict of interest: Nil

Permission from IRB: Yes

\section{References}

1. Cricco R.P. Kassis J 1970 MUCINOUS ADENOCARCINOMA of prostate, Urology 14;276-278

2. Jemal A Siegel R, Ward E, Murray T, Xu J, Smigal C, Thun 2006 Cancer statistics, 2006.CA Cancer J Clin56; 106-130

3. Hankey B F Feuer E J,Clegg L X 1999 Cancer surveillance series: interpreting trends in prostate cancer part1: evidence of the effects of screening in recent prostate cancer incidence mortality and survival rates.

4. Gittes RF.Carcinoma of the prostate.N Engl J Med 1991,324: 236-245.

5. Shimada H,Misugi K,Sasaki Y,lizuka A, NishihiraH.Carcinoma of the prostate in childhood and adolescence.Report of acase and review of the literature.Cancer 1980.

6. Babian RJ,Melttlin C kane R, Murphy GP, Lee F, Drago JR, ChesleyA.The relationship of prostatic specific antigen to digital rectal examination and transrectal ultrasonography.Finding of the American cancer society national prostate cancer Detection project.1992,69:11951200 .

7. McNeal JE,Redwine EA Freina FS 1988 Zonal distribution of prostatic adenocarcinoma.

8. Mostofi FK, Price EBJ. Tumors of the Male Genital System. vol. 8. Washington, DC: Armed Forces Institute ofP athology; 1973. 10.
9. Tumors of the Male Genital System[Atlas of Tumor Pathology, 2nd Series, Vol.8] [F. K. Mostofi, Edward B.

Price Jr.]

10. Humphrey PA. gleason Grading and prognostic factor in carcinoma of the prostate Modern Pathology (2004) 17, 292-306.

11. American Cancer Society, authors. Cancer Facts \& Figures 2007. Atlanta, GA: American Cancer Society; 2007.

12. Newcomer LM, Stanford JL, Blumenstein BA, Brawer MK. Temporal trends in rates of prostate cancer: declining incidence of advanced stage disease, 1974 to 1994. J Urol. $1997 ; 158: 1127-1130$

13. Carter HB, Piantadosi S, Isaacs JT. Clinical evidence for and implications of the multistep development of prostate cancer. J Urol. 1990;143:742-746

14. Scher HI, Isaacs JT, Zelefsky MJ, Prostate cancer. In: Abeloff MD, Armitage JO, Lichter AS,editors. Clinical Oncology. 2nd ed. New York, NY: Churchill Livingstone; 2000. pp. 1823-1884

15. Epidemiological aspects. In: Kirby RS, Christmas TJ, Brawer MK: Prostate Cancer. London, England: Mosby, 1996, pp 23-33

16. Dalkin BL,Fredrick R: PSA level in men without clinical evidence of prostatic carcinoma.J U $1933,15]: 1837-39$

17. AprikianAG,ZhangZF,Fair WR(1994) Prostate adenocarcinoma in men younger than 50 years Cancer,74,1768-77

18. Reissiggi A : Prostate carcinoma screening in the country of Tyrol, Austria.Cancer2000.Vol.80,issue9 page 1818-1829.

19. Newcomer LM, Stanford JL, Blumenstein BA. Temporal trends in rates of prostate cancer: declining 
incidence of advanced stage disease, 1974 to 1994. J Urol.

1997;158:1127-1130.

20. Etzioni R, Tsodikov A, Mariotto A. Quantifying the role of PSA screening in the US prostate cancer mortality decline. Cancer Causes Control 2008; 19:175.

21. Heijnsdijk EA, Wever EM, Auvinen A. Quality-of-life effects of prostate-specific antigen screening N Engl J Med 2012; 367:595.

22. Carter HB, Landis PK, Metter EJ. Prostate-specific antigen testing of older men. J Natl Cancer Inst. 1999;91:1733-1737.
23. Lilieby $\mathrm{W}$ Torlakovic $\mathrm{E}$ :Prognostic significance of histologic grading in patints with prostatic carcinoma who are assessed by Gleason and WHO grading systems in needle biopsies obtained prior to radiotherapy.Cancer2001:92:311-319.

24. Albertsen PC, Hanley JA, Fine J. 20-year outcomes following conservative management of clinically localized prostate cancer. JAMA. 2005;293:2095-21

25. Chin-Chen Pen,,Potter SR,Partin AW,Epstein JI:The prognostic significance of Tertiary Gleason pattern of higher grade in Radical Prostatectomy specimen.A proposal to modify the Gleason Grading system. Am J Surg pathol:2000:24:563-569

\section{How to cite this article?}

Jain VK, Khare V, Tantuway R. Study of Incidence of Carcinoma Prostate in Central India With Reference To Gleason's grading. Int J Med Res Rev 2013;1(4):169-176. doi: 10.17511/ijmrr.2013.i04.05 